\title{
DESIGN AND SIMULATION-BASED ANALYSIS OF A TEST BED FOR TWO- DIMENSIONAL KINEMATICALLY COUPLED FORCE COMPENSATION
}

\author{
S. Ihlenfeldt ${ }^{1,2}$, J. Müller ${ }^{1}$, M. Merx ${ }^{2 *}$, C. Peukert ${ }^{1}$ \\ 1 TU Dresden, Faculty of Mechanical Science and Engineering, Institute of Mechatronic Engineering, Chair of \\ Machine Tools Development and Adaptive Controls, Dresden, Germany \\ ${ }^{2}$ Fraunhofer Institute for Machine Tools and Forming Technology IWU, Dresden, Germany \\ *Corresponding author; e-mail: marcel.merx@tu-dresden.de
}

\begin{abstract}
To reduce the excitation of structural oscillations machine tools' feed dynamics are usually limited. Thus, their productivity is restricted, especially for high dynamic processes with negligible process forces. The principle of Kinematically Coupled Force Compensation (KCFC) tries to overcome this issue by combining a redundant axis configuration with the principle of force compensation.

In this paper, based on a short introduction considering the overall motivation and the KCFC principle, an overview of the design process of a 2D-KCFC test bed is given. This includes the simulation-based design of the slides, the machine frame and the electric voice coil drives. Subsequently a simulative analysis, facilitating a Multibody Simulation (MBS) for the investigation of the mechatronic system operated at highest feed dynamics and controller cycle rates, is performed. This simulation illustrates the possible reduction in process time and validates the effectiveness of the test bed's torque decoupling concept.
\end{abstract}

\section{Keywords:}

Linear Motor; Control; Compensation; Feed Drive; Redundant Axis

\section{INTRODUCTION}

Highly dynamic and yet precise motion control creates the basis for a multitude of recent machining and handling processes and enables their effective use. An example is the machining of optical functional elements by milling or even non-circular turning, where the requirements for high accuracy meet maximum productivity. Highly dynamic motion systems are also used in other areas of production, e.g. in the electronics and semiconductor industries. In these applications, motion dynamics are generally higher than that of machine tools of similar size.

In order to meet the increasing productivity requirements, more and more powerful drive systems are developed. For processes with low process forces, this implies the use of electric linear direct drives, which enable high accelerations and changes in acceleration (jerk). However, direct force application by linear motors increases the dynamic excitation of the machine structure. Thus, oscillations are generated and may be imprinted as contour or surface deviation in the workpiece [Hiramoto et al 2005]. Since the machines' moving components are designed as lightweight structures [Kroll 2011], machine frames are usually as massive and heavy as possible in order to suppress oscillations. An alternative approach is passive or active vibration reduction. Various principles are being pursued for this purpose (compare [Großmann 2014]):

- reduction of drive reaction forces by the use of redundant axis configurations [Schröder 2007],
- passive isolation (decoupling) at the point of force transmission into the machine frame (pulse decoupling, [Müller 2009]),

- complete decoupling of drive reaction forces from the machine frame (floating principle, [Buback 2003]),

- synchronous compensation of drive reaction forces (by force compensation, [Wang 2010] or impulse compensation, [Müller 2009]) and

- passive (e.g. Tuned Mass Damper - TMD), semiactive or active (e.g. Active Damping Device - ADD) systems [Brecher 2013])) generating a damping force effective against the excitation caused by the drive system.

The reduction of drive reaction forces within a redundant axis configuration combined with synchronous force compensation is applied by the Kinematically Coupled Force Compensation (KCFC).

This paper presents the main aspects of advanced design utilising the KCFC principle on the example of a planar motion system. In section 2 , the basic mechanical design of the 2D-KCFC test bed is discussed. This includes topology optimisation of the lightweight slides as well as the development of an approach for the reduction of vibration excitation resulting from dynamic torque caused by the drive reaction forces. Section 3 presents the tailored electrodynamic planar drive of the 2D-KCFC motion system. Subsequent to simulation-based design, first prototypes of the drive system's coils are shown. Section 4 deals with the MBS-modelling of the motion system. The created model is applied to assess the possible gain of process time as well as the effect of force compensation 
and torque decoupling on the example of high dynamic processes. Finally, section 5 summarises the results presented in this paper and gives an outlook on future research.

\section{DESIGN OF THE 2D-KCFC-MOTION SYSTEM}

\subsection{Basic Principle of KCFC and Concept of the} 2D-KCFC Test Bed

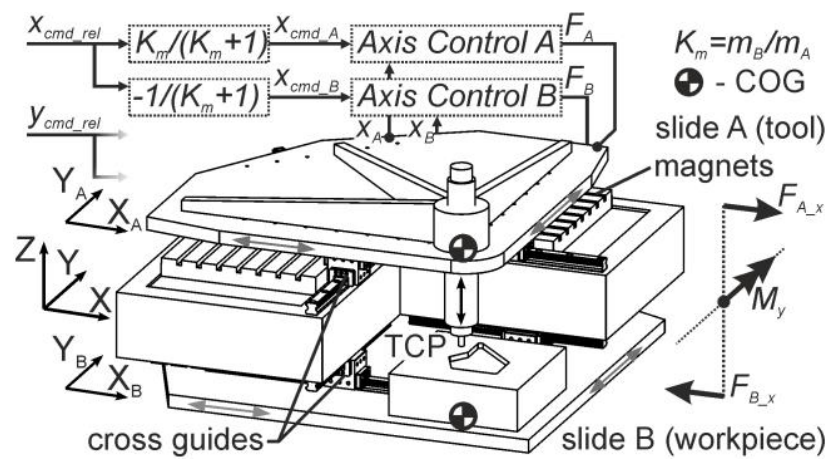

Fig. 1: Basic principle of KCFC on the example of the 2DKCFC arrangement, adapted from [Großmann 2019].

The KCFC utilises a parallel redundant axis configuration with distribution of motion based on a constant factor [Großmann 2019]. This factor $\mathrm{K}_{\mathrm{m}}$ is selected according to the mass ratio $m_{B} / m_{A}$ of the moving assemblies (see Fig. 1). Drive reaction forces $F_{A}$ and $F_{B}$ cancel out each other in the underlying machine structure. The traverse $X_{A}$ and $X_{B}$, velocity $V_{A}$ and $V_{B}$, acceleration $a_{A}$ and $a_{B}$ and jerk $j_{A}$ and $j_{B}$ add up at the TCP. In processes with variable slide masses, e.g. due to tool change or mass removal of the workpiece during milling, $\mathrm{K}_{\mathrm{m}}$ must be adjusted during processing.

In experimental investigations of 1D-KCFC the effectiveness of the principle could be confirmed [Ihlenfeldt 2019a]. An acceleration up to $20 \mathrm{~m} / \mathrm{s}^{2}$ and a jerk up to $50000 \mathrm{~m} / \mathrm{s}^{3}$ was realised. However, there is hardly any application background for the 1D-KCFC. Furthermore, other methods, such as the floating principle [Buback 2003], are superior for $1 \mathrm{D}$ motion. With transition to 2D-KCFC, the principle is more closely related to a real application background. Possible applications can be found in highly dynamic machining and handling with negligibly small process force and/or low workpiece mass. For that matter, 2D-KCFC can fully exploit its three essential advantages:

- higher feed dynamics at the TCP, synonymous with higher productivity,

- less energy consumption compared to a single axis, aligned with reduced power dissipation (heat), and

- low requirements on the machine frame regarding stiffness, mass and foundation.

For the 2D-KCFC test bed with planar motion, the demanded feed dynamics of the relative motion at the TCP are at least $V_{\text {max }} T C P=2 \mathrm{~m} / \mathrm{s}, \quad a_{\text {max_TCP }}=100 \mathrm{~m} / \mathrm{s}^{2}$ and $j_{\max \_T C P}=100000 \mathrm{~m} / \mathrm{s}^{3}$ in a square working area of $\mathrm{X}_{\max }=\mathrm{y}_{\max }=80 \mathrm{~mm}$ [Ihlenfeldt 2019b]. The mass ratio is anticipated with $\mathrm{K}_{\mathrm{m}} \approx 1$, which means the distribution of the relative motion to the slides in a ratio of $1: 1$. Since the test bed focuses on planar motion, the design of a Z-axis is omitted. Instead, a substitute mass of $5 \mathrm{~kg}$ is assumed.

Fig. 1 shows a simple design for 2D-KCFC with division of motion by $\mathrm{K}_{\mathrm{m}}$ and axis based position control (axis control). Alternatively, superimposed control loops [Großmann et a 2019] can be implemented, whereby the division of motion takes place just before the axis based velocity contro (superimposed position control) or just before the axis based current control (superimposed position and velocity control). In the case of superimposed position and velocity control, position measurement may be implemented directly between the two slides, utilising a planar measuring device. To achieve direct force flow at the slides, stacking of the $\mathrm{X}$ - and $\mathrm{Y}$-axes, e.g. as a cross table, must be avoided. Stacking would also lead to additional flexibility and geometric inaccuracies. Consequently, as indicated in Fig. 1, a planar guide (cross guide with profile rail guides) and an electrodynamic planar drive are used.

Fig. 2 illustrates the basic design as defined in [Ihlenfeldt 2019b] schematically and summarises the intended features of the 2D-KCFC test bed. The lightweight slides with electrodynamic planar drive should implement the application of drive forces at the centre of gravity (Drive at the Centre of Gravity principle according to [Hiramoto et al 2005]). Position measurement will be provided by absolute linear encoders relative to the guide frame and additionally between both slides by means of a planar measuring device (cross-grid encoder). The latter is advantageous for superimposed control strategies. Since $\mathrm{KCFC}$ is dedicated to highly dynamic motion, additional processing stations for subordinated processing should be provided [lhlenfeldt 2019b]. Since the slides are susceptible to vibration in Z-direction, the Z-axis unit to be developed later should operate without force feedback into the slides.

\section{Passive Vibration Isolation}

-passive isolation by decoupling of dynamic torque exitation by motor forces acting on magnet yokes -passive isolation by decoupling of the guide frame

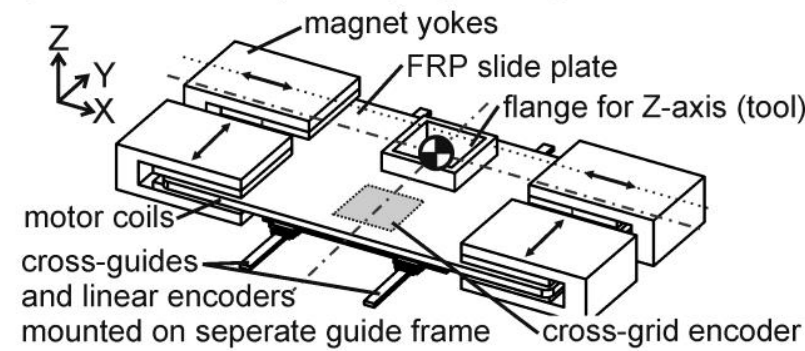

mounted on seperate guide frame

$\begin{array}{ll}\text { Measuring and Control } & \text { Machine Design } \\ \text {-cross grid encoder (rel. measuring) } & \text { •processing stations } \\ \text { - superimposed control } & \text {-reaction free Z-axis }\end{array}$

Fig. 2: Basic design of the slides and features for investigation of 2D-KCFC at the test bed, cf. [Ihlenfeldt 2019b].

Although the 2D-KCFC can ideally compensate drive reaction forces, dynamic torque excitation occurs because the planar drives are stacked in Z-direction (see $M_{y}$ in Fig. 1). By passive vibration isolation (decoupling) of the magnet yokes, a reduction of broadband torque excitation acting on the base frame can be achieved. Additionally the guide frame, which carries the linear guides and absolute encoders (see Fig. 4), may be isolated from the base frame. The approaches of vibration isolation enable the separation of the functionalities of guiding and measuring system from the force flow, which causes structural excitation. Thus, a higher accuracy should be achieved. The presented features result in numerous configurations, which will be investigated by means of simulations and, in future, by experiments at the real test bed. In the next section, the design of the mechanical components is discussed. 
2.2 Topology Optimisation and Design of the Lightweight Slides
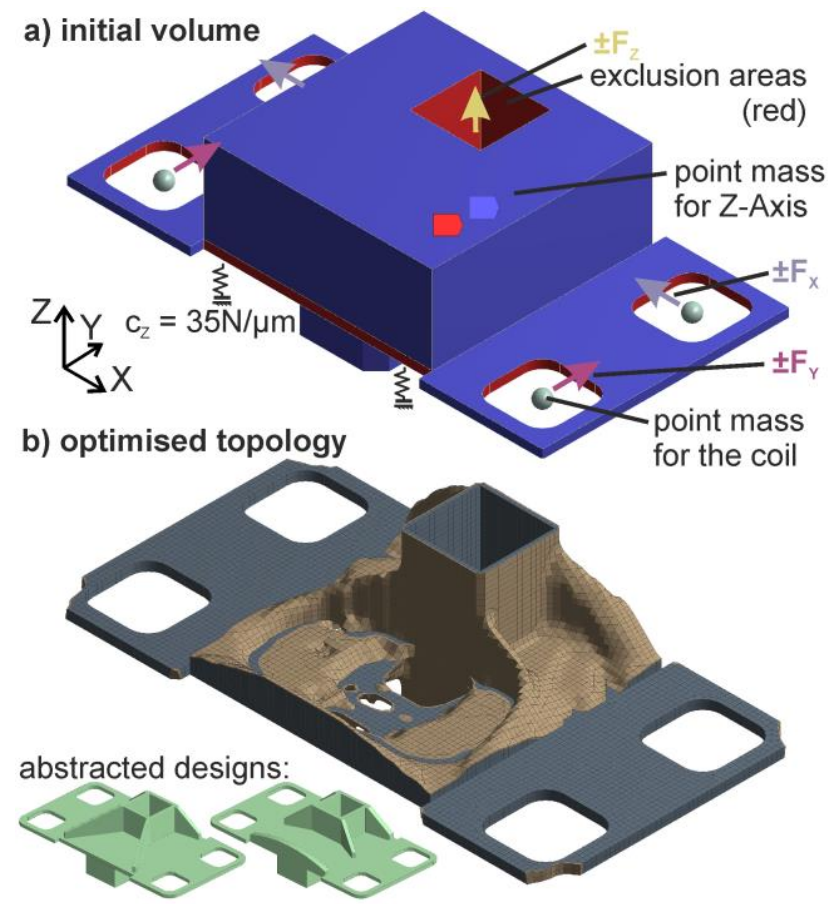

c) design concept

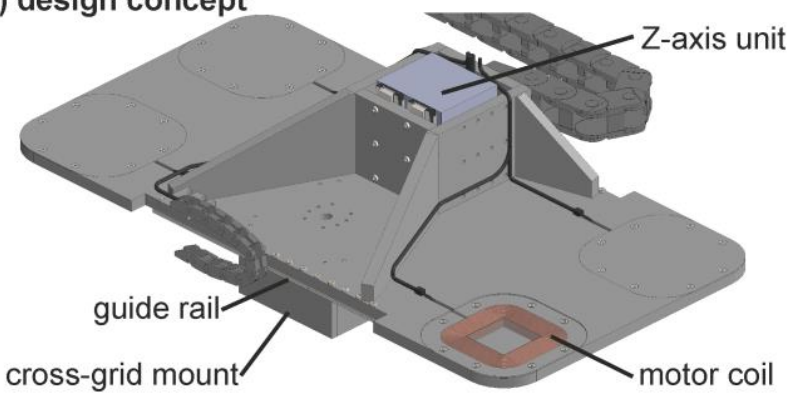

Fig. 3: Topology optimisation of the upper slide.

The core components of the 2D-KCFC motion system are the lightweight slides. They must be as light as possible, stiff at the same time and, above all, insensitive to vibrations. Since no electrically conductive materials must be used for the slide plates, a ribbed structure made of GFRP plates (commercially available material FR4) was selected. In order to optimise the arrangement of the ribs, a topology optimisation was carried out in ANSYS Workbench. It is based on an arrangement of four coils according to Fig. 2. Fig. 3a) depicts the initial volume and the exclusion areas for topology optimisation. The connection interfaces for the four linear guides (each assumed with $\mathrm{Cz}=35 \mathrm{~N} / \mu \mathrm{m}$ ) and the Z-axis unit, as well as the cavities for the coils, were excluded from optimisation. Topology optimisation was based on eight static load cases, covering all combinations of $F_{x}=F_{y}= \pm 500 N$ per coil and $F_{z}= \pm 250 N$ with the slide fixed in $\mathrm{X}$ - and $\mathrm{Y}$-direction at the $\mathrm{Z}$-axis interface, and a modal analysis. Static and modal analysis are weighted equally in topology optimisation. The modes 4 to 16 (excluding rigid-body modes) were taken into account, including the first bending mode of the slide plate. A slide mass of approx. $3.74 \mathrm{~kg}$ was reached by optimisation (cf. Fig. 3b). Considering the mass of the four coils (approx. $0.25 \mathrm{~kg}$ each), the target of a total slide mass of max $5 \mathrm{~kg}$ was achieved. The result of the topology optimisation was converted into a simplified ribbed slide construction. The ribs are to be pinned and glued. Z-axis and drag chains are suggested in Fig. 3c). The planar drives' coils are provided with a flange, inserted from above into the slide plate and secured with screws. The linear guide rails are screwed directly onto the machined GFRP plate.

\subsection{Simulative Analysis and Design of the Base Frame with Torque Decoupling}

In Fig. 4 the basic configuration of the 2D-KCFC test bed is shown. In front of and behind the KCFC processing station, two further processing stations can be set up later [Ihlenfeldt 2019b]. In order to approach these, the lower slide must be moved out of the magnet yokes. In the basic configuration the magnet yokes are directly connected to the base frame via solid spacers. The base frame itself is mounted on a heavy steel table (welding bench).

The cross guides for lower and upper slide are mounted on a separate guide frame that can be connected to the base with a variable number of connecting elements. If elastic connecting elements, such as rubber springs, are used, passive vibration isolation can be realised. Thereby higherfrequency excitations (above the rigid-body modes of the guide-frame mounted in the base frame) introduced at the magnet yokes, are damped during transmission to the guide frame (see decoupling modes in Fig. 5a). By this passive vibration isolation the excitation of the critical bending modes of the guide frame $\left(1^{\text {st }}\right.$ bending mode at approx. $300 \mathrm{~Hz}$, cf. [Ihlenfeldt 2019b]) and the slide $\left(1^{\text {st }}\right.$ bending mode $\sim 94 \mathrm{~Hz}$ [Ihlenfeldt 2019b]) can be reduced.

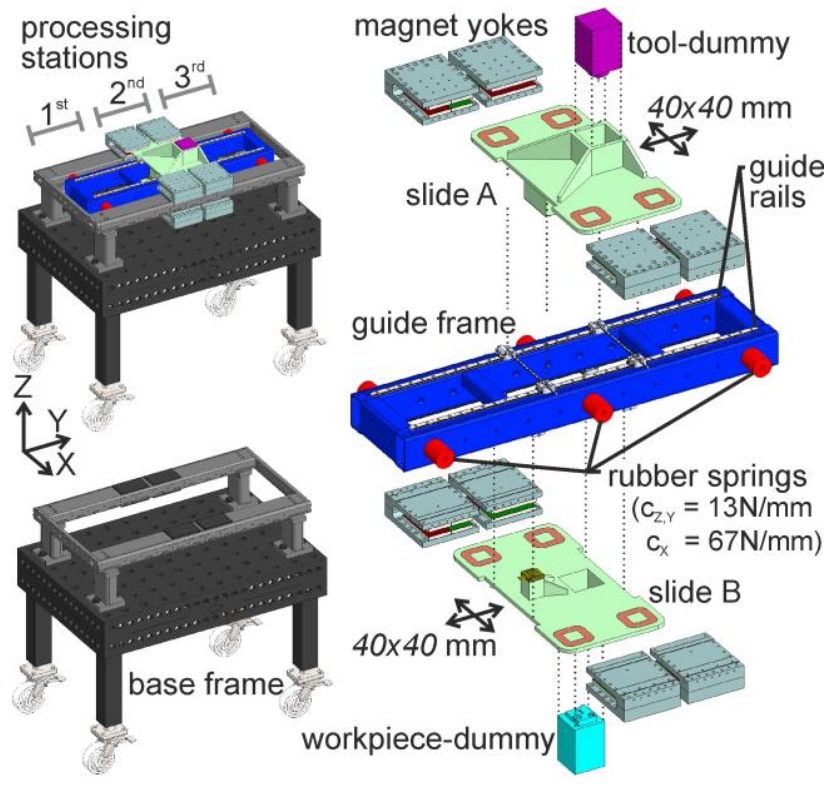

Fig. 4: 2D-KCFC test bed's structure, cf. [Ihlenfeldt 2019b].

In addition to the isolation of the guide frame, a passive isolation of the magnet yokes - the source of structural excitation - is designed. Fig. 5 b) and c) show two alternative principles of torque decoupling, based on rubber spacers or leaf springs as elastic elements. The mode of operation of both decoupling strategies is clarified by Fig. $5 \mathrm{~b}$ ) and c). For decoupling with rubber spacers, the magnet yokes are connected via adapter pieces to form a compact assembly. This encloses the support of the frame. If opposing drive reaction forces are exerted on the magnet yokes the yoke-assembly rotates and thus transfers the reaction torque in an attenuated way. Thereby decoupling reduces the bandwidth of the spectrum of dynamic torque excitation (low-pass filtering) transferred to the base frame. Compared to [Ihlenfeldt 2019b] the two rubber spacers (assumed an E-modulus of $111 \mathrm{~N} / \mathrm{mm}^{2}$ ) underneath each magnet yoke were reduced in size to achieve a lower decoupling frequency $(189.7 \mathrm{~Hz}$ instead of $338.2 \mathrm{~Hz}$ before). This is equal to a better isolation capability but 
increases the motion of the decoupling assembly. For MBSmodelling a lumped mass rotary oscillator can be assumed as analogous model according to Fig. 5b).

a) passive vibration isolation of the guide frame

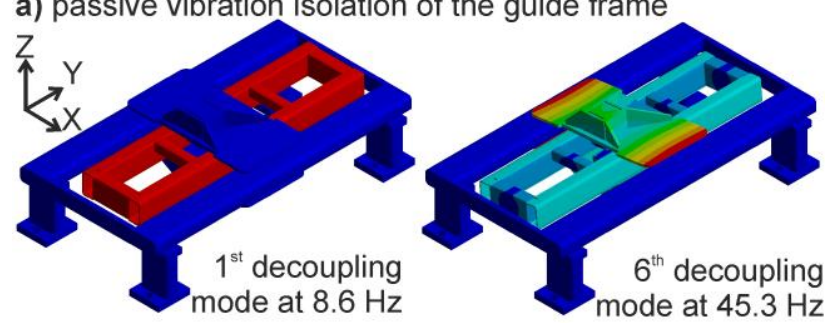

b) vibration isolation of magnet yokes with rubber spacers

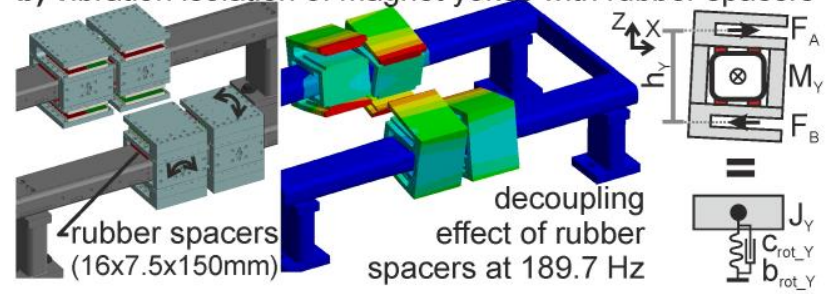

c) vibration isolation of magnet yokes with leaf springs

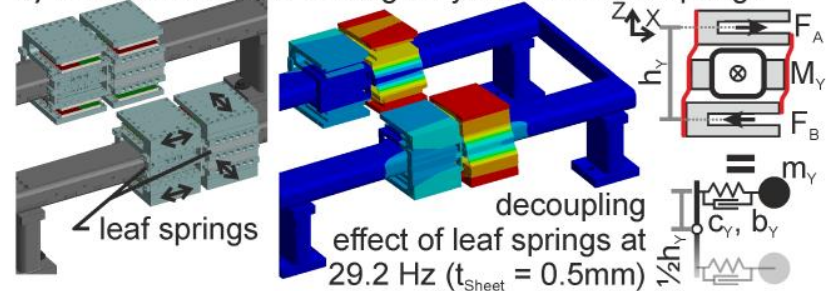

Fig. 5: Passive vibration isolation at 2D-KCFC test bed.

With decoupling using leaf springs a linear motion of the magnet yokes is unlocked (Fig. 5c). Thus, the dynamic force increases over the travel of the spring whereby the filter effect is achieved. A critical aspect of this design is its sensitivity to deviations of the eigenfrequencies of both spring-mass systems. If the system is off-tuned force or torque transmission into the base frame becomes asynchronous, which would reduce the effectiveness of compensation. As an analogous model, a single-mass oscillator considering transformation of force to torque by the factor $1 / 2 \cdot h_{Y}$ may be assumed (Fig. $5 c$ ). Compared to [Ihlenfeldt 2019b] the thickness of the leaf springs was reduced from 5 to $1 \mathrm{~mm}$ (decoupling in Y-direction) and from 2.5 to $0.5 \mathrm{~mm}$ (decoupling in $\mathrm{X}$-direction) to achieve a lower decoupling frequency $(29.2 \mathrm{~Hz}$ for the decoupling in X-direction instead of $193.6 \mathrm{~Hz}$ before).

The different isolation strategies result in four basic configurations for the frame structure of the test bed:

- without vibration isolation,

- with passive vibration isolation of the guide frame,

- with passive vibration isolation (torque decoupling) of the magnet yokes and

- with isolation of guide frame and magnet yokes.

An initial assessment of the effectiveness of torque decoupling is done in section 4, where a lumped parameter model according to Fig. $5 \mathrm{c}$ ) is used within MBS simulation. Prospective, the transfer behaviour of the passive vibration isolation in the frequency domain will be determined considering damping, analogously to [Ihlenfeldt 2019a].

\section{DESIGN OF THE PLANAR DRIVE SYSTEM}

\subsection{Basic Design of the Voice Coil Drives}

In order to achieve the most direct force flow and to enable the application of drive force at the centre of gravity of the slide (DCG principle), a planar drive is implemented. Since only small travels are required, an electrodynamic drive concept (moving coil) is realised. Motor coils and magnetic back iron are developed and manufactured in-house in order to adapt them optimally to the requirements of the 2DKCFC motion system. Fig. 6a) sketches one motor coil. A manufactured coil with foil winding is depicted in Fig. 6b). The rectangular coils have dimensions of $80 \times 80 \mathrm{~mm}$ and are completely covered by two permanent magnets, each $120 \times 60 \mathrm{~mm}$, located in the U-shaped magnet yoke (compare Fig. 7 a). This results in a travel of $40 \mathrm{~mm}$ in feed direction (Y-direction in Fig. 6 a). In addition, each coil can be moved $40 \mathrm{~mm}$ transversely to its feed direction without leaving the magnetic overlap.

The coil can be wound with round wire, litz wire, rectangular wire or copper foil (foil winding). Besides different electrical parameters, the winding designs have different mechanical and thermal properties. Sufficient mechanical stability is relevant, since each coil is loaded with $1 / 4$ of the feed force $F_{\text {coil }}$ as shear load at the transition of the two magnets (Fig. 6a). The nominal feed force is generated in approximately equal parts $\left(1 / 2 \mathrm{~F}_{\text {coil }}\right)$ by the coil sections lying completely below the magnets.

In order to find the best design and manufacturing technology for the coils, FE analyses are carried out and compared with measured values from real coils.

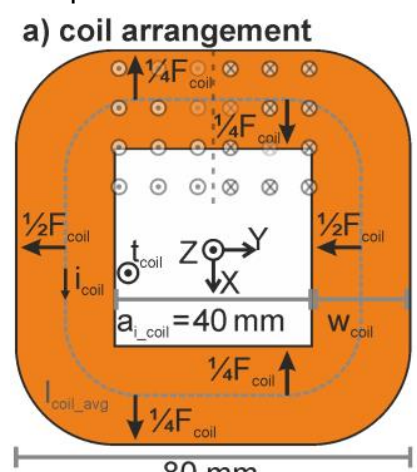

$80 \mathrm{~mm}$ b) manufactured coil (foil winding)

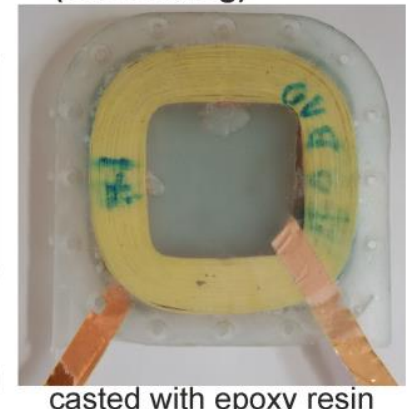

Fig. 6: Coil design for the planar drive.

\subsection{Simulation-assisted Design of Voice Coil Drives}

In [Ihlenfeldt 2019b] the design calculation of the voice coils was discussed in detail. The following equations are therefore not deduced. The motor force constant $\mathrm{k}_{\text {Mot }}$ can be calculated according to (1). It increases proportionally with the number of turns $\mathrm{N}_{\text {coil }}$ if all other values are assumed to be constant.

$\mathrm{k}_{\text {Mot }}=\frac{1}{2} \cdot \mathrm{I}_{\text {coil_avg }} \cdot \mathrm{N}_{\text {coil }} \cdot \mathrm{B}_{\text {air gap }} \sim \mathrm{N}_{\text {coil }}$

The achievable maximum acceleration of the motion system then results according to (2).

$a_{\text {max }}=\frac{k_{\text {Mot }} \cdot \mathrm{i}_{\text {max }}}{m_{\text {slide }}}=\frac{I_{\text {coil_avg }} \cdot \mathrm{N}_{\text {coil }} \cdot B_{\text {air gap }} \cdot \mathrm{i}_{\text {max }}}{2 \cdot \mathrm{m}_{\text {slide }}} \sim N_{\text {coil }} \cdot \mathrm{i}_{\text {max }}$

If one replaces $i_{\max } \cdot \mathrm{N}_{\text {coil }}$ (the total current linkage of the coil) with the equivalent expression $A_{\text {coil_eff'Smax (effective cross- }}$ sectional area of the coil multiplied by max. current density), according to (3) the achievable maximum acceleration in this case depends on the permissible current density $\mathbf{S}_{\max }$.

$a_{\max }=\frac{I_{\text {coil_avg }} \cdot A_{\text {coil_eff }} \cdot B_{\text {air gap }} \cdot S_{\text {max }}}{2 \cdot m_{\text {slide }}} \sim s_{\max }$

Thus, a high acceleration can be achieved by a high number of turns with low current, or less turns with correspondingly higher motor current. The maximum 
current provided by the amplifier or the applicable maximum current density of the conductor limit Smax.

On the other hand, the inductance $L_{\text {coil }}$ limits the maximum change in acceleration (the jerk) according to (4), if the voltage UPWM is limited and the other parameters except $\mathrm{N}_{\text {coil }}$ are assumed to be constant.

$\mathrm{j}_{\text {max }}=\frac{\mathrm{U}_{\mathrm{PWM}}}{\mathrm{L}_{\text {coil }}} \cdot \frac{\mathrm{k}_{\text {Mot }}}{\mathrm{m}_{\text {slide }}}$

$\mathrm{j}_{\text {max }}=\frac{\mathrm{U}_{\mathrm{PWM}}}{\mathrm{L}_{\text {coil }}} \cdot \frac{\mathrm{I}_{\text {coil_avg }} \cdot \mathrm{N}_{\text {coil }} \cdot \mathrm{B}_{\text {air gap }}}{\mathrm{m}_{\text {slide }}} \sim \frac{1}{\mathrm{~N}_{\text {coil }}}$

Since $L_{\text {coil }}$ is proportional to $\mathrm{N}_{\text {coil }}{ }^{2}$ (cf. [Ihlenfeldt 2019b]), the jerk is proportional to the reciprocal of the number of turns according to (5). Therefore, the lowest possible number of turns should be selected in order to achieve a high jerk. The associated low inductance $L_{\text {coil }}$ requires a high PWM frequency to keep the current ripple low.

\section{a) Geometry of the}

\section{Magnet Yoke (upper} plate hidden)

$$
\begin{aligned}
\mathrm{t}_{\text {coil }} & =10 \mathrm{~mm} \\
\mathrm{t}_{\text {air_gap }} & =12 \mathrm{~mm} \\
\mathrm{~B}_{\mathrm{R}_{\text {_magnet }}} & =1.35 \mathrm{~T} \\
\mu_{\text {rel_magnet }} & =1.05
\end{aligned}
$$

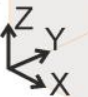

direction of magnetisation back iron (idealised material, $\mu_{\mathrm{r}}=10000$, saturation neglected)

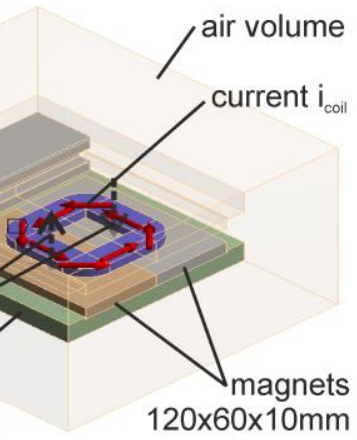

b) Magnetic Flux Density in the Magnet Yoke

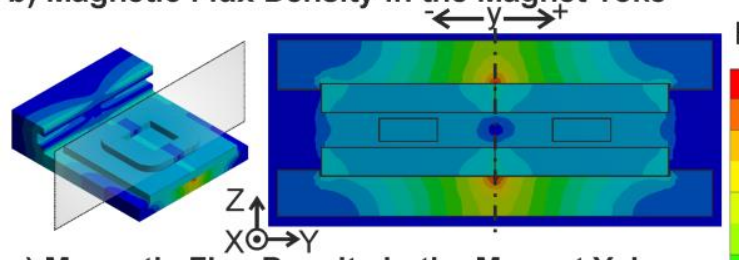

c) Magnetic Flux Density in the Magnet Yoke (coil excited with a current of $\mathrm{i}_{\text {coil }}=10 \mathrm{~A}$ )

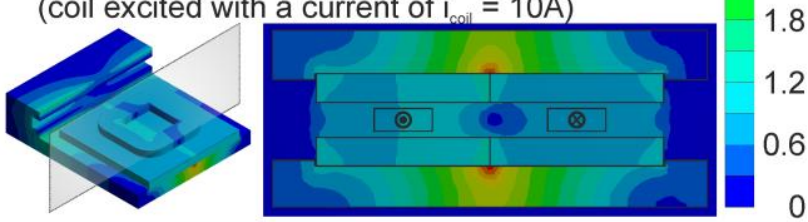

d) Position-dependent Motor Force $F_{\text {Mot }}(x, y)$ for $10 \mathrm{~A}$

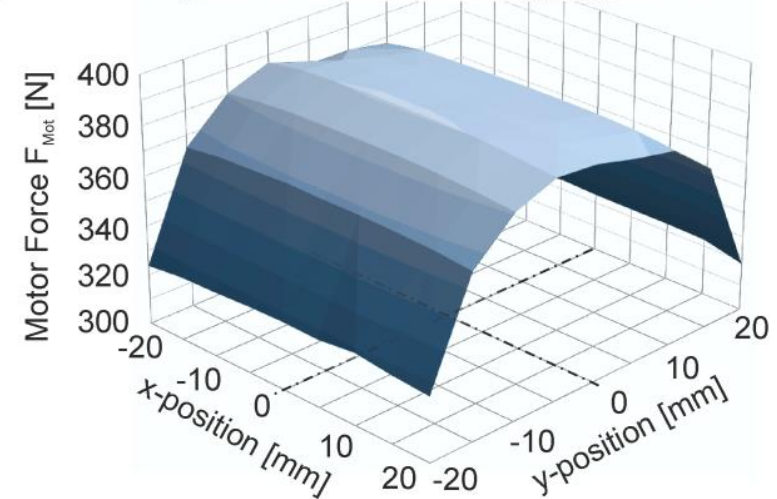

Fig. 7: Design and FE-Analysis of the magnetic circuit (parameters for coil SB2, according to Tab. 1).

The motor force can be calculated for a given current imax considering $\mathrm{k}_{\text {Mot }}$ from (1). The equations implemented for the analytical design with lumped parameters result in a constant force over the entire travel range. In fact, the motor force decreases towards the edges of the magnets because the magnetic flux density in the air gap $B_{\text {air_gap }}$ decreases. In order to estimate this effect quantitatively, an electromagnetic FE analysis was performed in ANSYS Workbench. The geometry and boundary conditions of the model are depicted in Fig. 7 a). In Fig. 7b) the magnetic flux density in the section of the magnet arrangement is illustrated. The decreasing flux density towards the edges of the magnets is clearly visible. If a motor current is defined, an additional displacement of the flux density distribution resulting from the magnetic field generated by the coil is evident (Fig. 7c). Besides the flux density distribution, the inductance of the coil in air and in the magnet yoke were derived by FE analysis (see Tab. 1).

If the excited coil (current of $10 \mathrm{~A}$ ) is successively moved through the entire travel path and across it, the realisable motor force $\mathrm{F}_{\mathrm{Mot}}(\mathrm{x}, \mathrm{y})$ can be determined as a function of position (see Fig. 7d). As expected, there is a drop of max. $18 \%$ in the motor force at the edges of the travel range. If necessary, the proportional gain of in the velocity or current control might be adjusted position-dependently in order to compensate for the drop of the motor force. Until now an idealised high permeable material with $\mu_{r}=10000$ and neglected magnetic saturation has been assumed for the modelling of the magnetic backing. The first experimental setup of a magnetic yoke will be realised with easily machinable mild steel (S355J2). Since reliable data for the relative permeability of this material is not available, material properties will be matched within simulation by comparison with an experimental setup according to Fig. 7a). If necessary, a highly permeable material, e.g. ARMCO, might be used for the magnetic yoke instead. Supplementary, an additional electrical excitation in the permanent magnet circuit will be assessed.

\subsection{Manufacturing and experimental Investigation of the Voice Coil Drives}

In order to evaluate the technologies for production of the coils, a total of eight coils in four design variants - according to the shapes of the wire cross sections available - were produced and measured. The coils were designed to have a similar wire cross-section in the order of $0.3 \mathrm{~mm}^{2}$. All coils were cast in a mould with epoxy resin (Fig. 6b) to provide inherent rigidity and ensure a backlash-free mechanical interface for mounting the coils in the slide (cf. Fig. 3c).

\begin{tabular}{|c|c|c|c|c|c|}
\hline $\begin{array}{l}\text { Coil } \\
\text { Type / } \\
\text { Wire } \\
\text { Section }\end{array}$ & $\begin{array}{l}\mathrm{N}_{\text {coil: }} \\
\text { act. } \\
(\max )\end{array}$ & $\begin{array}{l}R_{\text {coil: }} \\
\text { calc. / } \\
\text { meas. } \\
\text { in } \Omega\end{array}$ & $\begin{array}{c}\text { Lcoil_air: } \\
\text { calc./FEA / } \\
\text { meas. } \\
\text { in } \mathrm{mH}\end{array}$ & $\begin{array}{l}\text { Lcoil_yoke: } \\
\text { FEA } \\
\text { in } \mathrm{mH}\end{array}$ & $\begin{array}{l}\text { k } \text { Kot: } \\
\text { calc. / } \\
\text { FEA } \\
\text { in N/A }\end{array}$ \\
\hline $\begin{array}{l}\text { SB1 / } \\
\varnothing 0.6\end{array}$ & $\begin{array}{c}333 \\
(383)\end{array}$ & $\begin{array}{l}4.5 / \\
4.3\end{array}$ & $\begin{array}{c}8.3 / 7.5 / \\
7.9\end{array}$ & 15.6 & $\begin{array}{r}31 / \\
33\end{array}$ \\
\hline $\begin{array}{l}\text { SB2 / } \\
\varnothing 0.6\end{array}$ & $\begin{array}{c}391 \\
(428)\end{array}$ & $\begin{array}{l}5.2 / \\
5.1\end{array}$ & $\begin{array}{c}11.2 / 10.3 / \\
10.9\end{array}$ & 21.6 & $\begin{array}{l}36 / \\
39\end{array}$ \\
\hline $\begin{array}{c}F W 1 / \\
10 \times 0.035\end{array}$ & $\begin{array}{c}196 \\
(363)\end{array}$ & $\begin{array}{l}2.1 / \\
2.1\end{array}$ & $\begin{array}{c}2.8 / 2.6 / \\
3.4\end{array}$ & 5.4 & $\begin{array}{l}18 / \\
19\end{array}$ \\
\hline $\begin{array}{c}\text { FW2 / } \\
9 \times 0.035\end{array}$ & $\begin{array}{c}241 \\
(363)\end{array}$ & $\begin{array}{l}2.6 / \\
3.0\end{array}$ & $\begin{array}{c}4.4 / 3.9 / \\
4.1\end{array}$ & 8.2 & $\begin{array}{l}22 / \\
24\end{array}$ \\
\hline
\end{tabular}

Tab. 1: Coil parameters (values FEA for middle position, measurement of $R_{\text {coil }}$ using multimeter Voltcraft VC940 and $L_{\text {coil }}$ using inductivity meter Miernik RLC type E317).

Calculated, simulated (finite element analysis - FEA) and measured data for the two most promising coil designs (coils made of self baking enamelled wire SB1 and SB2 and copper foil FW1 and FW2) are presented in Tab. 1. These variants have proven to be suitable since they allow a mechanically stable coil construction and high bulk factor. 
According to Tab. 1, the electrical parameters can be well predicted by analytical calculation and FEA as well. Only the calculation of the inductance under consideration of the magnet yoke is not feasible in an analytical way. The influence of the inductance on the achievable feed dynamics (jmax according to (4)) thus justifies the implementation of a FEA. The parameters of the coil SB2 are used for the MBS modelling and analysis in section 4 . In the future, it should be possible to increase the bulk factor up to the theoretical values (compare $\mathrm{N}_{\text {coil }}$ in brackets in Tab. 1) by improving the winding technology.

\section{MBS-MODELLING AND EVALUATION ON THE EXAMPLE OF HIGH DYNAMIC PROCESSES}

\subsection{MBS-Modeling of the 2D-KCFC Motion System}

control mechanical system electrical circuit

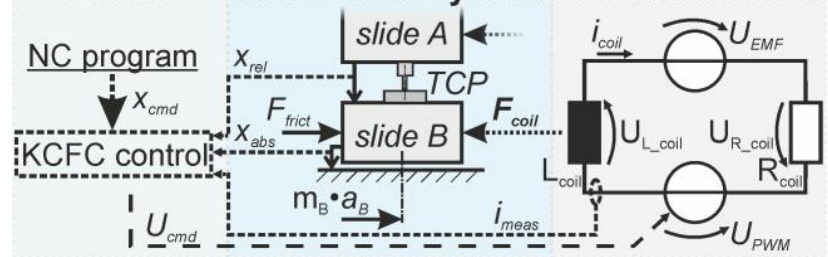

Fig. 8: MBS model of the test bed, cf. [Ihlenfeldt 2019b].

Tab. 2: Parameters of the MBS-model (parameters marked with * are varied in a range of $+/-5 \%)$.

\begin{tabular}{|c|c|c|c|}
\hline Parameter & Value & Parameter & Value \\
\hline lide $\operatorname{mass}_{1 / 2} \cdot \mathrm{m}_{\mathrm{B}} 1 / 2 \cdot \mathrm{m}_{\mathrm{A}}$, & $1 / 2 \cdot 10 \mathrm{~kg}$ & $\begin{array}{l}\text { cur. measuring } \\
\text { resolution } \Delta_{\text {cur }}\end{array}$ & $0.6 \mathrm{~mA}$ \\
\hline mass of yoke $\mathrm{my}$ & $9.38 \mathrm{~kg}$ & $\begin{array}{l}\text { cur. measuring } \\
\text { noise } n_{c u r}\end{array}$ & $\begin{array}{c}2.5 \mathrm{~mA} \\
\mathrm{RMS}\end{array}$ \\
\hline stiffn. (yoke) cy & $0.317 \mathrm{~N} / \mu \mathrm{m}$ & $\begin{array}{l}\text { proportional gain } \\
\left(\text { pos.) } \mathrm{K}_{v}\right.\end{array}$ & 600 \\
\hline damping (") by & $6358 \mathrm{Ns} / \mathrm{m}$ & vel. LP-filter $\mathrm{T}_{\text {vel }}$ & $50 \mu \mathrm{s}$ \\
\hline $\begin{array}{l}\text { stiction force } \\
1 / 2 \cdot f_{\text {stic }}{ }^{*}\end{array}$ & $1 / 2.9 .6 \mathrm{~N}$ & $\begin{array}{l}\text { cur. measuring } \\
\text { bandwidth } f_{\text {cur }}\end{array}$ & $500 \mathrm{kHz}$ \\
\hline $\begin{array}{l}\text { sliding force } \\
1 / 2 \cdot \text { slid }^{*}\end{array}$ & $1 / 2 \cdot 4.6 \mathrm{~N}$ & $\begin{array}{l}\text { cur. measuring } \\
\text { delay Tdelay_cur }\end{array}$ & $1 \mu \mathrm{s}$ \\
\hline $\begin{array}{l}\text { stict. stiffness } \\
\text { Cstic }\end{array}$ & $0.15 \mathrm{~N} / \mu \mathrm{m}$ & $\begin{array}{l}\text { vel. feed-forward } \\
\text { factor } \mathrm{K}_{\mathrm{ff} \_ \text {vel }}\end{array}$ & 1 \\
\hline $\begin{array}{l}\text { visc. friction } \\
1 / 2 \cdot b_{s l i d}{ }^{*}\end{array}$ & $1 / 2 \cdot 17.9 \mathrm{Ns} / \mathrm{m}$ & $\begin{array}{l}\text { proportional gain } \\
\text { (velocity) } K_{p}\end{array}$ & $750 \mathrm{As} / \mathrm{m}$ \\
\hline force const. $\mathrm{k}_{\mathrm{Mot}}$ & $36 \mathrm{~N} / \mathrm{A}$ & $\begin{array}{r}\text { inte } \\
\text { cons }\end{array}$ & $0.025 \mathrm{~s}$ \\
\hline back-EMF kEMF & $36 \mathrm{Vs} / \mathrm{m}$ & cur. LP-filter $\mathrm{T}_{\text {cur }}$ & $25 \mu \mathrm{s}$ \\
\hline resistance* $R_{\text {mot }}$ & $5.0 \Omega$ & $\begin{array}{r}\text { acc. fe } \\
\text { fact }\end{array}$ & 1 \\
\hline inductivity ${ }^{*} \mathrm{Lmot}$ & $10.9 \mathrm{mH}$ & $\begin{array}{r}\text { propor } \\
\text { (cur }\end{array}$ & $272.5 \mathrm{~V} / \mathrm{A}$ \\
\hline $\begin{array}{l}\text { controller cycle } \\
\mathrm{T}_{\text {pos }}=\mathrm{T}_{\text {vel }}=\mathrm{T}_{\text {cur }}\end{array}$ & $10 \mu \mathrm{s}$ & $\begin{array}{l}\text { integral time } \\
\text { const. (cur.) } \mathrm{T}_{\mathrm{I}}\end{array}$ & $0.0022 \mathrm{~s}$ \\
\hline $\begin{array}{l}\text { pos. measuring } \\
\text { resolution } \Delta_{\text {pos }}\end{array}$ & $0.305 \mathrm{~nm}$ & PWM frequ. fPWM & $100 \mathrm{kHz}$ \\
\hline $\begin{array}{l}\text { pos. measuring } \\
\text { noise } n_{\text {pos }}\end{array}$ & 20 nm RMS & $\begin{array}{c}\text { PWM-voltage } \\
\text { UPWM }\end{array}$ & $100 \mathrm{~V}$ \\
\hline $\begin{array}{l}\text { pos. measuring } \\
\text { bandwidth } \mathrm{f}_{\text {pos }}\end{array}$ & $500 \mathrm{kHz}$ & current limit lim & $20 \mathrm{~A}$ \\
\hline $\begin{array}{l}\text { pos. measuring } \\
\text { delay } T_{\text {delay_pos }}\end{array}$ & $1 \mu \mathrm{s}$ & $\begin{array}{l}\text { lever arm of the } \\
\text { yokes hy (Fig. } 5 c)\end{array}$ & $0.133 \mathrm{~m}$ \\
\hline
\end{tabular}

For simulation-based analysis of system behaviour, a MBSmodel of the test bed was created in MATLAB/Simulink (Fig. 8). Because of symmetry, only half a slide with one drive for the $\mathrm{X}$ - and $\mathrm{Y}$-direction is modelled.

The mechanical model includes the moving slides as lumped masses and considers a non-linear LuGre friction model according to [Brecher 2011] for simulation in time domain. For analyses in the frequency domain, only viscous friction force is taken into account. The machine frame has not been modelled yet. However, the effect of torque decoupling (see sketch in Fig. 5c) is estimated by simple mechanical models.

The electrical model comprises the inductance of the coils as well as the generation of the PWM signal. The control is designed as cascaded position, velocity and current control, whereby a PID controller is provided for each cascade. However, the parameterisation was initially implemented as a typical P-PI-PI cascade. Control is implemented timediscrete, taking typical values for the resolution of optical position measuring systems (with $20 \mu \mathrm{m}$ grating period and 16 Bit interpolation) as well as current measuring with a resolution of 16 Bit into account. Signal noise and limited bandwidth of the position and current measurement are also considered. The model parameters are listed in Tab. 2. Currently these only represent a first approximation and thus allow qualitative statements on system behaviour. The current controller was adjusted in the linearised model using the optimum amount. Velocity and position control were set according to the open loop frequency response. Controller gains had to be lowered based on time domain simulation with the nonlinear model in order to achieve a stable control behaviour.

\subsection{Highly dynamic Processes}

The milling of a small workpiece, the assembly of electronic components by pick and place and wire bonding were selected as example processes for deriving realistic motion profiles for simulation-based evaluation of the 2D-KCFC motion system. For each process, dynamic parameters for conventional machines (cf. [Ihlenfeldt 2019b]) as well as parameters achievable with a 2D-KCFC kinematic are defined in Fig. 9 below.

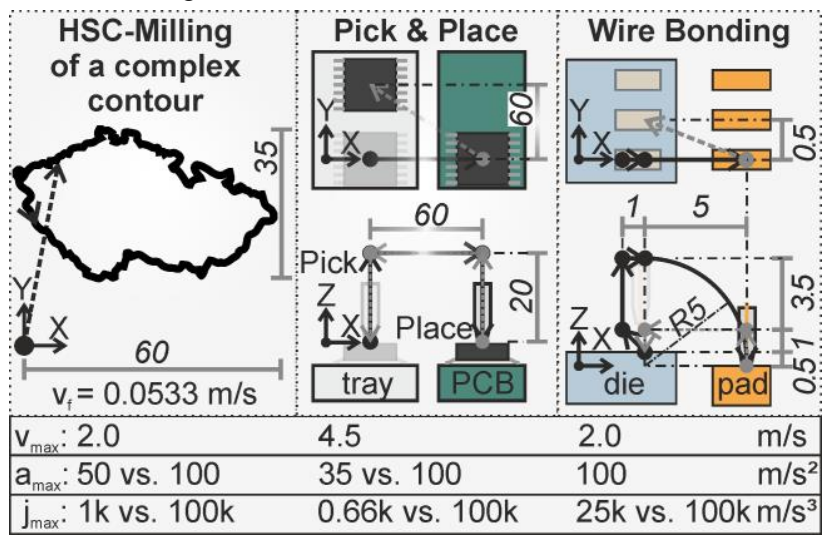

Fig. 9: Example Processes with Feed Dynamics.

Due to the process, the feed rate $v_{f}$ during milling is limited. The maximum feed rate is only reached in rapid traverse, e.g. when approaching the contour. In milling processes, the largest variety and complexity of trajectories is present. In contrast, the assembly of electronic components (pick and place) has similar dynamic requirements, but simple point-to-point motions are carried out with comparatively large strokes. The highest dynamic requirements can be found in the wire bonding process. For pick and place and 
wire bonding it is assumed that there are no technologically determined limitations for the feed dynamics.

\subsection{Process Time Reduction and Effect of Torque Decoupling}

a) HSC-Milling $\quad t_{\text {conv }}=9.03 \mathrm{~s} \quad t_{\mathrm{KCFC}}=3.84 \mathrm{~s}$
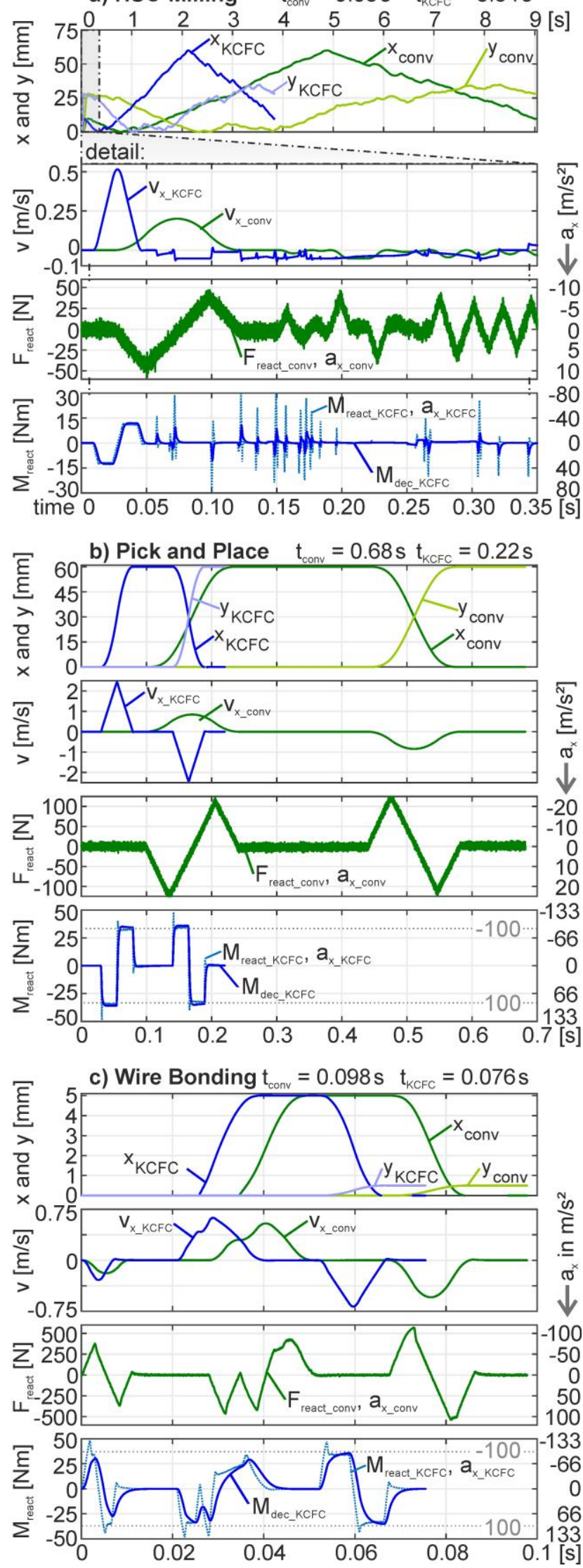

Fig. 10: MBS-simulation results (for processes cf. Fig. 9).
For comparison, a single slide of the 2D-KCFC kinematic is used as a substitute for a conventional machine 'conv'. Fig. 10 shows the actual position and velocity for the low dynamic (conventional - 'conv') process as well as for the high dynamic ('KCFC') process. In addition, drive reaction forces for the conventional kinematic and the dynamic torque with and without decoupling for the KCFC kinematic are shown for each process.

Based on the simulation results shown in Fig. 10, the possible reduction of process time for all three exemplary processes becomes evident. The corresponding time is written above the respective diagram. In HSC-milling (Fig. 10a), the decrease in machining time is mainly achieved by the shorter acceleration phases, while the feed rate $v_{f}$ during milling is limited to $53.3 \mathrm{~mm} / \mathrm{s}$. The utilisation of the acceleration capacity of the KCFC is clearly shown by the velocity-time curves or acceleration-time curves (see detail in Fig. 10a) below). The acceleration values $a_{x}$ are proportional to the reaction forces $F_{\text {react }}$ or reaction torques Mreact (acceleration values are plotted on the right-hand scale). In contrast, the velocity limitation is not reached at the pick and place process (Fig. 10b). However, there are phases with constant acceleration, i.e. the acceleration limitation becomes effective with the KCFC for that process. This is typical for highly dynamic handling processes, which are usually not subject to any technologically induced speed limitation. A similar result is obtained for wire bonding, where KCFC enables to move longer at constant acceleration, which is due to the higher jerk value.

The reaction forces $F_{\text {react }}$ are severely noisy. This directly reflects the discretisation considered in the MBS model as well as the assumed signal noise. Since there are practically no reaction forces present using KCFC, the critical reaction torques Mreact are considered in Fig. 10. These can reach orders of magnitude of up to $50 \mathrm{Nm}$ on very steep slopes. In order to reduce the resulting broadband excitation, the dynamic torques should be decoupled (cf. Fig. 5). Since decoupling with rubber pads has only a low effectivity, the corresponding results have not been presented. On contrary, the decoupling with leaf springs works very well, as the profiles of the 'decoupled' torque Mdec, which is transferred to the machine frame, indicate. The maximum amplitudes of $\mathrm{Mreact}_{\text {are }}$ damped and the gradients are visibly smoothed. The maximum deflections of the decoupled magnet yokes are less than $1 \mathrm{~mm}$ and therefore uncritical.

The KCFC cannot reduce the contouring error, as it combines two conventional single axes. As a result, the errors of both slides add up at the TCP. A higher control bandwidth may be achieved with KCFC in the case of a base frame oscillation that limits the performance of the controller's position loop. However, it is difficult to compare the achievable contouring errors because the KCFC is based on fundamentally different kinematics and construction. To evaluate the control bandwidth and motion accuracy, a real test system has to be utilised. Due to its redundant axis configuration the KCFC offers the possibility of implementing extended control concepts. Of particular interest is the combination of KCFC with modal control (cf. [Peukert 2019]), as the latter is capable of damping the vibrations of the moving assembly itself by utilising the feed drives.

\section{SUMMARY AND OUTLOOK}

In this paper, the main aspects of advanced design of highly dynamic motion systems utilising the KCFC principle were presented on the example of a planar motion system. 
Based on the definition of requirements for the motion system, the mechanical structure was concretised. The two slides of the motion system were designed as plate structures and optimised for high stiffness with low mass by means of topology optimisation. The mechanical design of the machine frame had to be completely rethought in order to achieve the opposite arrangement of the slides and a direct force flow for the KCFC. It is necessary to take the dynamic torque excitation resulting from force introduction in two Z-planes into account. This is unavoidable if the force application is to be realised in the centre of gravity of the slides (DCG). In order to reduce the excitation, a passive vibration isolation was designed, on the guide frame, as the most vibration-sensitive part, and on the magnet yokes, as main source of the excitation. The developed torque decoupling with leaf springs already achieves a good decoupling effect, which is illustrated by the simulative analyses in section 4 . Decoupling with rubber pads must be further improved with regard to the lowest possible natural frequency of the decoupling assembly. This is to be achieved by adapting the arrangement and geometry of the rubber elements.

The desired feed dynamics can be achieved by using electrodynamic planar drives. These are analytically designed as shown in section 3 . For the determination of the coils' inductance in the magnet yokes as well as for the evaluation of the position-dependent motor force constant, a FEA was carried out. Considering the nearly doubled inductance due to the influence of the magnet yokes, the number of turns should be as low as possible to achieve low inductivity and thus high jerk. This requires correspondingly higher motor currents in order to achieve the motor force required for the desired acceleration capacity.

Using a simple MBS model, the gain of process time and the effect of torque decoupling to reduce structural excitation were investigated for three highly dynamic example processes. The possible reduction in process time is significant. The effect of passive vibration isolation of the guide frame could not yet be evaluated. But, based on the results obtained for the decoupling of the magnetic yokes, the isolation concept seems very promising.

The next step in development of the 2D-KCFC motion system is the detailed design of the slides and the base frame, whereby the decoupling with rubber pads will be optimised with regard to a lower decoupling frequency. The manufactured coils for the electrodynamic drives will be examined experimentally with regard to their motor force constant and inductance in the magnet yoke. Based on previous findings, improved coils with a higher filling factor are to be manufactured and tested. The investigation of their mechanical strength and thermal behaviour is also part of future investigations.

Another important aspect is the selection of the linear and planar measuring devices, the control system and the drive amplifier. In this respect, comparative simulations with the MBS model will be carried out. In particular, the influence of discretisation and signal noise have to be evaluated. Finally, the lumped parameter model of the test will be extended to an elastic MBS model and adjusted based on measurement results from the real test bed.

\section{ACKNOWLEDGMENTS}

This research was funded by the German Research Foundation (DFG) within the project „Development and analysis of principles for Kinematically Coupled Force-
Compensation for machine tools" $(\mathrm{IH} 124 / 8-2)$, which is gratefully acknowledged. Additional thanks go to our students Clemens Kumpe, who supported us with topology optimisation of the slide plates, to Johannes Feigel, who did the electromagnetic FE-analysis of the drive systems and to Dirk Böhlke, who built and measured the motor coils.

\section{REFERENCES}

[Brecher 2011] Brecher, C., Kunc, M. Reibkraftmodellierung von Profilschienenführungen. wt-online, Vol.101, No.5, pp. 328-338.

[Brecher 2013] Brecher, C., Baumler, S., Brockmann, B. Avoiding chatter by means of active damping systems for machine tools. Journal of Machine Engineering, Vol.13, No.3, pp. 117-128.

[Buback 2003] Bubak, A., Soucek, P., Zelený, J. New Principles for the Design of Highly Dynamic Machine Tools. Proceedings of the international conference ICPR-17, Blacksburg Virginia (USA), pp. 1-10.

[Großmann 2014]. Großmann, K., Müller, J., Merx, M., Peukert, C. Reduktion antriebsverursachter Schwingungen. Antriebstechnik / ant Journal. 2014, Vol.53, No.4, pp. 35-42.

[Großmann 2019]. Großmann, K., Müller, J., Merx, M. German patent specification DE102012101979B4.

[Hiramoto 2005] Hiramoto, K., Hansel, A., Ding, S., Yamazaki, H., A study on the drive at the Centre of Gravity (DCG) feed principle and its application for development of high performance machine tool systems, CIRP Annals Manufacturing Technology, Vol.54, No.1, pp. 333-336.

[Ihlenfeldt 2019a] Ihlenfeldt, S., Müller, J., Merx, M. and Peukert, C. Kinematically Coupled Force Compensation Experimental Results and Advanced Design for the 1DImplementation. Journal of Manufacturing and Materials Processing, 2019, Vol.3, No.1, pp. 1-13. ISSN 2504-4494

[Ihlenfeldt 2019b] Ihlenfeldt, S., Müller, J., Merx, M. and Peukert, C. Design Approach for high-dynamic planar Motion Systems based on the Principle of Kinematically Coupled Force Compensation. Journal of Machine Engineering, 2019, Vol.19, No.2, pp. 5-17.

[Kroll 2011] Kroll, L., Blau, P., Wabner, M., Frieß, U., Eulitz J., Klärner, M. Lightweight components for energy-efficient machine tools. CIRP Journal of Manufacturing Science and Technology, 2011, Vol.4, No.2., pp. 148-160.

[Müller 2009] Müller, J., Vergleichende Untersuchung von Methoden zur Verringerung der Gestellanregung durch linearmotorgetriebene Werkzeugmaschinenachsen. diss. TU Dresden.

[Peukert 2019] Peukert, C., Pöhlmann, P., Merx, M., Müller, J. and Ihlenfeldt, S. Investigation of Local and Modal Based Active Vibration Control Strategies on the Example of an Elastic System. Journal of Machine Engineering, 2019, Vol.19, No.2, pp. 32-45.

[Schröder 2007] Schroeder, T., Krabbes, M. and Neugebauer, R. Reactive trajectory splitting function for machine tools with hierarchical drive structures. The International Journal of Advanced Manufacturing Technology. 2007, Vol.33, No.9-10, pp. 988-993.

[Wang 2010] Wang, Z.G., Cheng, X., Nakamoto, K., Kobayashi, S., Yamazaki, K. Design and development of a precision machine tool using counter motion mechanisms. International Journal of Machine Tools and Manufacture, Vol.50, pp. 357- 